\title{
Combating Bacterial Adhesion and Protein Deposition on Cosmetic Contact Lenses Using Zinc Oxide Nanoparticles
}

\author{
Eman Araby ${ }^{(1) \#}$, Hanan S. El-Bastawisy ${ }^{(2)}$ and Seham Y. El-Tablawy ${ }^{(2)}$ \\ ${ }^{(1)}$ Radiation Microbiology Department, National Centre for Radiation Research and \\ Technology (NCRRT), Egyptian Atomic Energy Authority (EAEA), P.O. Box 29, Nasr \\ City, Cairo, Egypt; (2) Drug Radiation Research Department, National Centre for \\ Radiation Research and Technology (NCRRT), Egyptian Atomic Energy Authority \\ (EAEA), P.O. Box 29, Nasr City, Cairo, Egypt.
}

\begin{abstract}
CONTACT lenses (CLs) are frequently used for medical or cosmetic purposes. Readily available cosmetic contact lenses (CCLs) sold at night market and lack of awareness, represent the main reasons for microbial keratitis (MK) and consequently losing sight. MK arises from bacterial contamination of lenses, lens casing and solutions. Improper handling and unhygienic use of the CLs allow pathogens to adhere and produce biofilm on its surface. This study aims to evaluate the adherence ability of pathogenic bacterial strains isolated from worn CCLs and the potentiality of zinc oxide nanoparticles ( $\mathrm{ZnO} N \mathrm{NP}$ ) on their colonization in absence and presence of two types of deposited proteins. The results revealed that all the isolated strains had the ability to produce strong biofilm. ZnONPs highly affected the biofilm formation ability of the tested strains and significantly decreased their adherence on the tested proteins coated lenses. Using scanning field emission electron microscopy; extensive colonization covering CCLs surface of control and lysozyme coated lenses was observed. While micrographs illustrated that ZnONPs are effective in restraining bacterial colonization with deformed cells on the surface of lysozyme coated lenses. In addition, the data exhibited that $75 \%$ of the tested packaging solutions were highly contaminated with bacteria, so they were subjected to increasing doses of gamma- radiation. The results proved that $6.0 \mathrm{kGy}$ was sufficient to eliminate bacterial bio burden of the tested solutions. It may be hoped that the present study will encourage efforts towards the development of novel antibacterial agents against microbial infection of CCLs.
\end{abstract}

Keywords: Cosmetic contact lenses, Protein coated lenses, Zinc oxide nanoparticles, Bacterial adhesion, Gamma- radiation.

\section{Introduction}

The use of CCLs has become increasingly popular, especially in teenagers causing significant complications such as microbial keratitis, if they are not handled properly (Chan et al., 2014). Microbial keratitis is defined as an inflammation of corneal tissue due to direct infection by microbial agents such as bacteria, fungi, protozoa, and viruses. It is the most dangerous complication occurs in response to contact lens wear which can potentially be devastating to the cornea (Prasannakumary \& Jyothy, 2017).

Microbial growth is characterized as a biofilm when the microorganisms attach to a surface and/or to each other. Biofilms are a population of multilayered cells growing on a surface and enclosed in exopolysaccharide matrix. Microbial biofilm formations are considered to be a twostep process in which the bacteria first adhere to a surface, followed by multiplication to form a multilayered biofilm. Biofilms offer increased antibiotic resistance to microorganisms as compared to the planktonic/free-living mode of growth. Microbial adhesion on contact lenses and lens storage cases may be a risk factor for contact lenses associated corneal infections (Kackar et al., 2017).

The tear film is composed of mucin layer, proteins, and lipids (Ohashi et al., 2006 and Pucker et al., 2010). During contact lenses wear; proteins and lipids can adhere to the surface of CLs as reviewed by Luensmann \& Jones (2008). Some novel approaches have been studied as potential strategies to prevent this adhesion such as quorum sensing inhibitors, antimicrobial

\footnotetext{
\#Corresponding author email: emansk2@gmail.com_ Mobil phone: (+002) 01094886248

DOI: 10.21608/ejrsa.2018.2092.1030

C2018 National Information and Documentation Center (NIDOC)
} 
peptides, enzymes and nanomaterials (NMs). Among the above methods, nanotechnology is a highly promising one. NMs possess antimicrobial and antibiofilm properties against various bacterial, fungal and other microorganism species; consequently, NMs could serve as a costeffective, easy-to-use alternative to inactivate microorganisms.

Microbes are more unlikely to develop resistance against NPs since they attack a broad range targets which requires the microorganism to develop defence mechanisms. $\mathrm{ZnO}$ in nanoscale has shown strong antimicrobial activities on a broad spectrum of microbes, and great potential for microbial control and restriction of biofilm formation (Liu et al., 2017).

Gamma irradiation process utilizes highenergy photons that are emitted from an isotope source (Cobalt 60) producing ionization (electron disruptions) throughout a product. It is ideal for a variety of medical device applications including, the sterilization of single-use medical supplies such as syringes, implants, catheters, surgical gloves and gauze. It is also ideal for the elimination of organisms from pharmaceuticals such as ointments and solutions and sterilization of tissue/biological based products (Ražem, 2008).

The purpose of this study is to determine the bacterial colonization of worn CCLs, examining the adhesion capacity among the isolated organisms and the potentiality of ZnONPs on their biofilm production was evaluated. Also, we compared the influence of protein deposition (lysozyme and bovine serum albumin) as individual major tear proteins on bacterial adhesion on CCLs in presence and absence of ZnONPs supported by field emission electron microscopy examination. Finally, the microbial load of the packaging solution of CCLs was estimated to determine the effective decontamination gamma- radiation dose.

\section{Materials and Methods}

Samples collection, isolation and identification of cultures

A total of 100 of worn cosmetic contact lenses (CCLs) were collected from microbial keratitis cases from different clinics and hospitals in Grand Cairo, Egypt.
The contact lenses were aseptically immersed into Brain Heart Infusion (BHI) (SigmaAldrich) broth tubes and vortexed for 1 minute. Subsequently, the lenses were removed and the tubes were incubated at $37^{\circ} \mathrm{C}$ for $24 \mathrm{~h}$. After incubation, a loop full of broth was inoculated on the nutrient agar (Sigma-Aldrich) plates which incubated at $37^{\circ} \mathrm{C}$ for $24 \mathrm{~h}$ (Abidi et al., 2013). The cultures were identified by using conventional and rapid biochemical tests (API 20E and API STAPH systems).

\section{Antibiogram assay of the tested strains}

All the isolates were tested for their susceptibilities to antibiotics by the disc diffusion agar method (Bauer et al., 1966) in accordance with Clinical and Laboratory Standard Institute's recommendations (CLSI, 2007). The following conventional antibiotic discs $(\mu \mathrm{g})$ (Oxoid) were used; amoxicillin (AML 30), cephalexin (CL 30), gentamicin (CN10), sulphamethoxazoletrimethoprim (SXT 25) and ceftrixone (CRO 30). Petri plates were prepared with $15 \mathrm{ml}$ of sterile Mueller Hinton Agar. The tested cultures were swabbed on the top of the solidified medium and allowed to dry for $10 \mathrm{~min}$. Then antibiotic discs were placed on the surface of the medium. The plates were incubated for $24 \mathrm{~h}$ at $37^{\circ} \mathrm{C}$. Zones of inhibition were recorded in millimeters and interpreted referring to standard chart (Oxoid). Experiments were performed in triplicate and the values were then averaged.

Detection of biofilm formation by tissue culture plate method (TCP)

The TCP assay is the most widely used and was considered a standard test for detection of biofilm formation. All isolates were screened for their ability to form biofilm as described by Christensen et al. (1985). Tested strains from fresh agar plates were inoculated in trypticase soy broth with $1 \%$ glucose and incubated for $24 \mathrm{~h}$ at $37^{\circ} \mathrm{C}$ in stationary condition and diluted with fresh medium. Individual wells of sterile, polystyrene, flat-bottom tissue culture plates were filled with $0.2 \mathrm{ml}$ aliquots of the diluted cultures containing about $\left(2 \times 10^{5} \mathrm{CFU}\right)$ and only broth served as control to check sterility and non-specific binding of media. Following $48 \mathrm{~h}$ of incubation at $37^{\circ} \mathrm{C}$, the contents of tissue culture plates were gently aspirated with a micropipette. The plates were then washed with sterile buffer, adherent organisms were fixed by incubating them for $1 \mathrm{~h}$ at $60^{\circ} \mathrm{C}$ and then staining them 
with crystal violet $(1 \%)$ for $5 \mathrm{~min}$. After washing using water to remove the excess stain, the plates were dried for $30 \mathrm{~min}$ at $37^{\circ} \mathrm{C}$. Optical densities (ODs) of stained adherent biofilms were obtained with Microplate Reader-Suno Stick SPR-960B at $595 \mathrm{~nm}$. Experiments for each strain were performed in triplicate.

\section{Anti-adhesive activity of $\mathrm{ZnONPS}$}

$\mathrm{ZnO}$ nanoparticles $(<50 \mathrm{~nm}$ diameter, catalog number 677450-5G) were purchased from Sigma-Aldrich and were characterized using UV spectrophotometer JASCO V-560, Japan. Different concentrations of $\mathrm{ZnO}-\mathrm{NPs}$ were well dispersed in distilled water ranging from 0.1 to $5.0 \mathrm{mM}$ and $100 \mu \mathrm{l}$ was added to each well of 96 well microtiter plate containing $100 \mu \mathrm{l}$ of bacterial suspensions of the strongest biofilm producer tested strains $\left(1.5 \times 10^{8} \mathrm{CFU} / \mathrm{ml}\right)$ and then the test was accomplished as previously mentioned. Assays were performed in triplicate.

\section{Protein coating on contact lenses}

New unworn CCLs were removed from their packaging and thoroughly rinsed in sterile

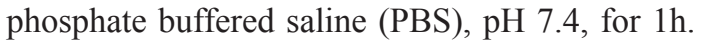
to ensure that no packaging solution remained on the lens surface. Lysozyme (EGG with activity $>20,000 \mathrm{U} / \mathrm{ml}$ Bioshop ${ }^{\circledR}$ Canada Inc, Burlington) and bovine serum albumin (Loba, India) solutions were prepared at a concentration of 1.9 and $0.5 \mathrm{mg} /$ $\mathrm{ml}$, respectively. The lenses were incubated for 5 days, and then they, were removed from the vials and washed in a plate shaker with PBS to remove loosely bound protein (Subbaraman et al., 2011).

\section{Anti-adherence effect of ZnONPs on protein coated CCLs}

Un-coated CCLs used as control and two sets of protein-coated lenses were placed in a 24-well plate containing $1 \mathrm{ml}$ of $24 \mathrm{~h}\left(1.5 \times 10^{8} \mathrm{CFU} / \mathrm{ml}\right)$ bacterial suspension of the most susceptible tested strains to ZnONPs treatment (P.aeruginosa 10 and Enterobacter cloacae 13). One $\mathrm{ml}$ of ZnONPs, at the most potent concentration $(2.5 \mathrm{mM})$ was added to one set of the protein coated lenses while the other remained without treatment. The plates were incubated at $37^{\circ} \mathrm{C}$ for $24 \mathrm{~h}$, and then, lenses were washed three times in $1 \mathrm{ml}$ of sterile phosphate buffered saline (PBS) for $30 \mathrm{sec}$ each time, transferred to a sterile $5 \mathrm{ml}$ plastic container and vortexed vigorously for $1 \mathrm{~min}$ in $2 \mathrm{ml}$ of sterile PBS, using sterile magnetic stirring bars. For quantitation of viable bacteria per a contact lens, the homogenate was serially diluted in PBS $1: 10$ by taking $100 \mu \mathrm{l}$ and adding it to $900 \mu \mathrm{l}$ of neutralizing broth in a microcentrifuge tube. Fifty microliters of the serially diluted samples were plated in triplicate on nutrient agar plates and incubated for $18 \mathrm{~h}$ at $37^{\circ} \mathrm{C}$. The number of colonies per dilution were recorded and used to calculate the number of CFU per a contact lens. Each assay was repeated in triplicate, and then the average values were computed to enumerate the viable counts of bacteria adhered to contact lenses.

\section{Cell-surface hydrophobicity}

Cell-surface hydrophobicity has been implicated to enhance the ability of microbes to form biofilms and to influence cell clumping. This was investigated using microbial adhesion to hydrocarbons assay (Perez et al., 1998). Overnight cultures of tested strains (control and treated with different concentrations from ZnONPs) grown in LB broth, were pelleted by centrifugation at $10,000 \mathrm{rpm}$ for $5 \mathrm{~min}$ and subsequently washed twice using PBS. Cells were adjusted to an optical density of 0.5 at OD600 and $2 \mathrm{ml}$ mixed with $400 \mu \mathrm{l}$ xylene and vortexed for $2 \mathrm{~min}$. After $30 \mathrm{~min}$ incubation at room temperature, the aqueous phase was collected carefully and its OD600 was determined. The OD600 of the aqueous phase relative to the initial suspension was taken as a measure of cell-surface hydrophobicity ( $\mathrm{H} \%)$, which was calculated with the formula:

$$
\mathrm{H} \%=[(\mathrm{OD} 0-\mathrm{OD}) / \mathrm{OD} 0] \times 100
$$

where OD0 and OD are the optical density of control and after treatment with ZnONPs.

\section{Field emission electron microscopy (FEM)}

Two sets of lysozyme coated lenses (prepared as previously mentioned), one set of them was treated with $2.5 \mathrm{mM}$ of $\mathrm{ZnONPs}$ and the other without treatment. While Uncoated CCLs used as control, then lenses were incubated with $1 \mathrm{ml}$ of $18 \mathrm{~h}$. $\left(1.5 \times 10^{8} \mathrm{CFU} / \mathrm{ml}\right)$ of the tested bacterial suspension. Samples were processed for field emission electron microscopy, and fixed in $2.5 \%$ glutaraldehyde at room temperature for $30 \mathrm{~min}$. then, fixative solution was removed and the samples were rinsed three times with sodium cacodylate $0.1 \mathrm{M}$ buffer and dehydrated using a series of alcohols (30-100\%). Finally, they were sputter-coated with gold under vaccum and were examined in the FE-SEM 5800 Agilent. 
Microbiological quality of packaging solution of CCLs

Twenty CCLs packaging solutions were used, from each sample; $1 \mathrm{ml}$ was serially diluted with sterile physiological saline. Then, appropriate dilutions were used in enumeration of bacterial counts on tryptone-glucose yeast extract (TGY) plates containing $100 \mu \mathrm{g} / \mathrm{ml}$ mycostatin (antifungal) and incubated at $32 \pm 1{ }^{\circ} \mathrm{C}$ for $24-48 \mathrm{~h}$. While the fungal counts were determined on sabouraud dextrose plates containing $100 \mu \mathrm{g} / \mathrm{ml}$ oxy-tetracycline hydrochloride(antibacterial) and incubated at $28 \pm 1^{\circ} \mathrm{C}$ for 3-5 days. The experiment was repeated in triplicate and the average number was recorded (Shah \& Pokhrel, 2012).

\section{Irradiation process}

The irradiation process was achieved using Cobalt $60\left({ }^{60} \mathrm{Co}\right)$ Gamma Cell GC 220, product of Canada Co. Ltd. located at the National Center for Radiation Research and Technology (NCRRT) Cairo, Egypt. The irradiation process was achieved at ambient temperature. The dose rate of this source was $1.538(\mathrm{kGy} / \mathrm{h})$ at the time of the experiment.

\section{Determination of $\gamma$-irradiation decontamination} dose of the packaging solutions

To determine the decontamination dose level, appropriate aliquots of contaminated solutions were exposed in Epindorff tubes to $\gamma$-radiation at different doses $(1,2,3,4,5$ and $6 \mathrm{kGy})$. The irradiated and non- irradiated samples were analyzed for microbial load as previously mentioned.

\section{Statistical analysis}

The results were shown as mean values. The data were evaluated by analysis of variance (ANOVA). According to the results of the ANOVA test Duncan's multiple range test was used to determine the significance at $\mathrm{P}<0.05$ levels (Steel \& Torrie 1980).

\section{Results and Discussion}

Samples collection, cultivation and identification of bacterial isolates

A total of 100 worn CCLs were subjected to microbiological analysis. Out of these samples; 84 lenses $(84 \%)$ were positive for bacterial infection while all samples were negative for fungal infection. From 84 positive cases; eighteen isolates were obtained and identified on the basis of their morphology and Gram reaction. Eleven isolates were Gram +ve cocci, while seven isolates were
Gram -ve rods. All isolates were identified by API system and revealed the isolation of nine species belonging to five genera represented in Fig. 1. Among the isolated pathogens, Staphylococci are the most common isolates followed by $P$. aeruginosa. Al- Mujaini et al. (2009) reported that $P$. aeruginosa, Haemophilus and Moraxella cause infectious keratitis in extended wear CCL users. In a study performed by Benhmidoune et al. (2013), they found that the isolated pathogens were Staphylococcus aureus, P. aeruginosa and Acanthamoeba. Dyavaiah et al. (2015) concluded that infectious keratitis with CL wear is caused mostly by Gram negative bacteria as $P$. aeruginosa, Gram positive bacteria as $S$. aureus or fungi as Fusarium solani.

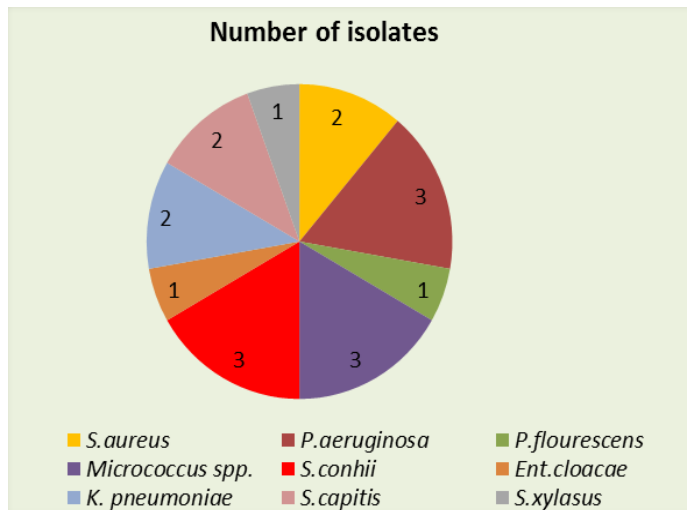

Fig. 1 Distribution of the isolated pathogens from 100 worn of CCLs.

Antibiogram assay of the isolated strains

Antibiotic resistance among the ocular pathogens has become a major medical and public health problem. So, all isolates were tested for its antibiotic sensitivity using Kirby Bauer disk diffusion method. This test was carried out towards (SXT, CL, CRO, CN and AML), which are commonly used in the treatment of MK as reported by Sueke et al. (2010) and Willcox (2012). The results presented in Fig. 2 revealed that most of pathogens showed a high percentage of resistance towards all the tested antibiotics.

\section{Biofilm formation ability of the tested strains}

Microbial infections in the biomedical implants pose a serious threat in modern medicine. Biofilms are high density population of bacteria that are embedded in an extracellular polysaccharide matrix. Its production is an important pathogenic factor which facilitates adherence of microorganisms to medical devices and protects them from the host immune system and antimicrobial therapy (Iannitelli et al., 2011). 


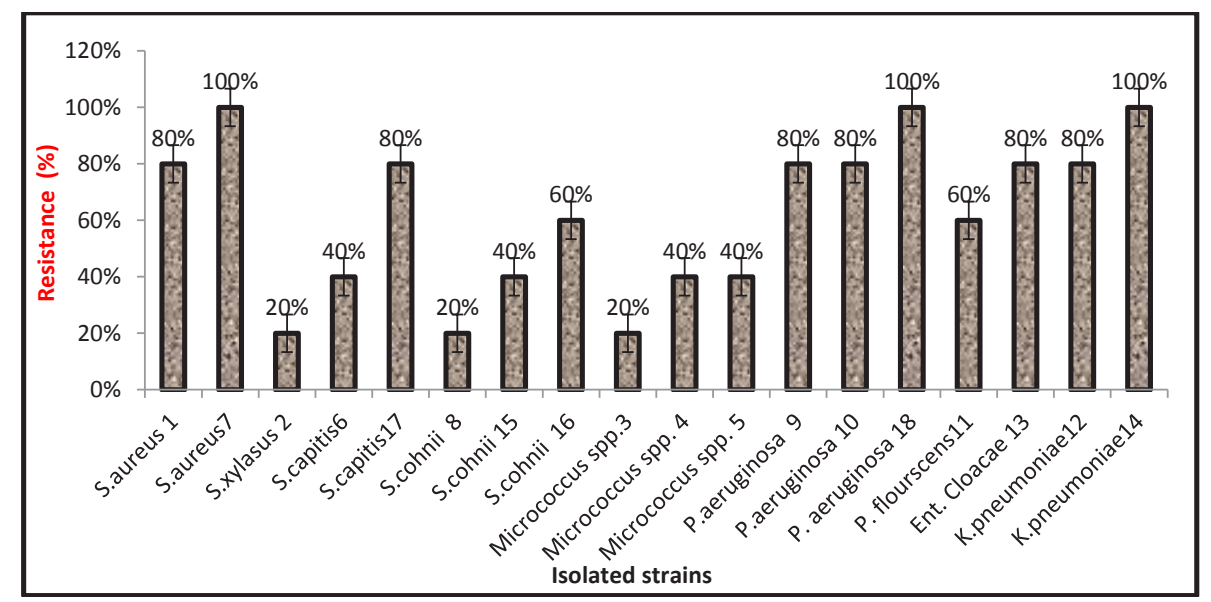

Fig. 2. Antibiogram assay for the isolated strains to the selected antibiotics.

Mathur et al. (2006) reported that the TCP method is considered as an accurate method for screening and determination of biofilm production. Therefore, in the current study, all strains were subjected to quantitative assessment of biofilm formation by spectrophotometric method. Table 1 revealed that all isolates produced a significant biofilm under the conditions utilized in the present experiments, except two species of Micrococcus produced moderate biofilm. Bacterial biofilms have been demonstrated on CLs obtained from patients with keratitis as reported by Shimizu et al. (2006).

Mah \& O'Toole (2001) and Jhanji et al. (2007) reported that there was an increase in antibiotic resistant bacteria contaminated CLs including $P$. aeruginosa where biofilm formation of $P$. aeruginosa is a mechanism of antibiotic resistance, because biofilm cells are much more resistant to antibiotics than planktonic cells. The ability of $P$. aeruginosa ATCC 10145 and a clinical strain (obtained from active ulcerative keratitis) to produce biofilms on CLs was tested by Sewell et al. (2014), they reported that the tested clinical strain was four times stronger to produce a biofilm than the standard one.

\section{Characterization of ZnNPS by UV-vis spectroscopy}

$\mathrm{ZnO}$ nanoparticles were tested using UVVis spectral analysis. Fig. 3 illustrates that the absorption peaks for $\mathrm{ZnO}$ nanoparticles were intensively absorbed in the ultraviolet band in the range of 300-500nm wavelength range in UV-Vis spectra that are assigned to $\mathrm{ZnO}$ nanoparticles. The spectrum showed the absorbance peak at $365 \mathrm{~nm}$ corresponding to the characteristic band of $\mathrm{ZnO}$ nanoparticles.
TABLE 1. Biofilm formation ability of the isolated strains.

\begin{tabular}{lc}
\hline Isolated strains & Adherence ability (O.D)* \\
\hline S.aureus 1 & $0.34 \pm 0.01$ \\
S. Xylosus 2 & $0.36 \pm 0.03$ \\
Micrococcus spp. 3 & $0.31 \pm 0.02$ \\
Micrococcus spp. 4 & $0.22 \pm 0.02$ \\
Micrococcus spp. 5 & $0.21 \pm 0.01$ \\
S.capitis 6 & $0.25 \pm 0.004$ \\
S.auerus 7 & $0.29 \pm 0.02$ \\
S.cohnii 8 & $0.56 \pm 0.12$ \\
P.aeruginosa 9 & $0.49 \pm 0.06$ \\
P.aeruginosa 10 & $\mathbf{0 . 7 6} \pm \mathbf{0 . 0 2}$ \\
P.flourescens 11 & $\mathbf{0 . 7 6} \pm \mathbf{0 . 0 2}$ \\
K.pneumoniae 12 & $\mathbf{0 . 7 5} \pm \mathbf{0 . 0 3}$ \\
Ent. Cloacae 13 & $\mathbf{1 . 0 5} \pm \mathbf{0 . 0 4}$ \\
K.pneumoniae 14 & $0.29 \pm 0.003$ \\
S. cohnii 15 & $\mathbf{0 . 6 8} \pm \mathbf{0 . 0 1}$ \\
S.cohnii 16 & $0.61 \pm 0.01$ \\
S.capitis 17 & $0.33 \pm 0.001$ \\
P.aeruginosa 18 & $0.46 \pm 0.025$ \\
\hline Was &
\end{tabular}

*Values are mean of three replicates \pm the standard error. Weakly -adherent $\mathrm{ODs} \leq 0.12$, moderately $(0.120<\mathrm{ODs} \leq 0.24)$, strongly $(\mathrm{ODs}>0.24)$

Anti-adhesive activity of $\mathrm{ZnONPS}$

The upcoming approach towards control of biofilm formation involves nano materials that have been designed to prevent bacterial infection on CCLs and subsequently biofilm formation including incorporation of silver nanoparticles and selenium as reported by Mathews et al. (2006) and Willcox et al. (2010). 


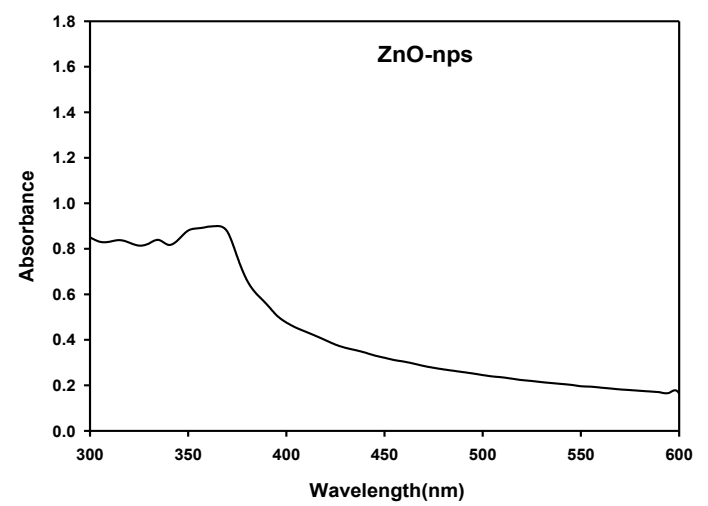

Fig. 3. UV-vis of ZnONPs

In the present study, the potent biofilm producer strains were tested towards different concentrations of ZnONPs. Figure 4 demonstrates that by increasing concentration of ZnONPs, the ability of all strains to produce biofilm was decreased. Also, it was found that $2.5 \mathrm{mM}$ was the most potent concentration causing a significant inhibition for biofilm formation. Several studies documented that $P$. aeruginosa is the most causative organism for M.K.; fortunately, $P$. aeruginosa 10 was aggressively affected by ZnONPs changing from strong $(\mathrm{O} . \mathrm{D}=1.17)$ to weak producer $(\mathrm{O} . \mathrm{D}=0.271)$. The same result was observed for Ent. cloaceae 13 which changed from strong $(\mathrm{O} . \mathrm{D}=1.001)$ to weak producer with $\mathrm{O} . \mathrm{D}=0.122$. Similar results were obtained by Lee et al. (2014) and Sangani et al. (2015), where they reported that ZnONPs can inhibit the establishment of $P$. aeruginosa biofilms and virulence factor production. In another study conducted by Ansari et al. (2014), they confirmed the high efficacy of AgNPs on biofilm eradication and reduction the applied surface coverage by E. coli and Klebsiella spp. thus prevent the biofilm formations. Dhillon et al. (2014) explained the potential inhibitory effect of ZnONPs on tested bacterial biofilm through inhibition of exopolysaccharides section.

\section{Effect of protein coating on bacterial adhesion}

Bacteria have the ability to adhere differently to various worn and unworn contact lenses. It was suggested that the increase in adhesion for certain strains to worn lenses may be due to the tear components containing proteins that are most likely bound to the contact lenses were favourable to bacterial adhesion (Willcox et al., 2001).
This experiment was performed to determine the adhesion of $P$. aeruginosa 10 and Ent. cloacae 13 onto CCLs with and without (lysozyme $\&$ albumin). Generally, the data revealed that coating CCLs with lysozyme increased significantly $(\mathrm{P}<0.05)$ binding (total viable count) of the tested strains when compared to un-coated lenses. While there were no significant differences $(\mathrm{P}>0.05)$ in the total viable counts of the tested strains bound to albumin coated and un- coated lenses. These results are in accordance with a pervious study conducted by Thakur et al. (1999), where they reported that lysozyme deposits on contact lenses increased the adhesion of several strains of Staphylococcus to etafilcon A lenses. On the other hand, Taylor et al. (1989) established that $S$. epidermidis and $P$. aeruginosa adhered significantly higher with increasing concentration of albumin on contact lenses.

Subbaraman et al. (2011) suggested that different tear proteins have varying effects on the adhesion of bacteria to contact lens materials. Lysozyme deposits on contact lenses increase the adhesion of Gram positive Staphyloccocus aureus 31 strain, while albumin deposits increase the adhesion of both the Gram positive Staphyloccocus aureus and Gram negative Pseudomonas aeruginosa 6206 \& 6294 strains. Meanwhile, Lactoferrin deposits increase the total counts of both the Gram positive and Gram negative strains

Another study performed by Omali et al. (2013), indicated that lysozyme/lactoferrin combination increased the adhesion of only a single strain of $S$. aureus 031, while lipocalin did not affect the adhesion of any of the tested strains.

\section{Anti-adherence effect of ZnONPs on protein coated CCLs}

Contact lenses develop protein and lipid deposits from tears during wearing that enhance bacterial adhesion (Omali et al., 2013). This experiment was done to determine the impact of $\mathrm{ZnONPs}$ on adherence of the selected strains on lysozyme and bovine albumin serum coated CCLs. Results in Fig. 5 appeared that the adhesion of $P$. aerugionsa 10 and Ent. cloacae 13 on lysozyme coated CCLs increased by one log cycle, comparing to uncoated lens. The results also proved that treatment of CCLs with ZnONPs reduced the adhesion by two and one 
log cycles for the tested strains, respectively. On the other hand, slightly increase in the adhesion of both of the tested strains was noticed on bovine serum albumin coated lenses. By treatment with ZnONPs, the adhesion decreased by two and one $\log$ cycles for $P$. aerugionsa 10 and Ent. cloacae 13, respectively. The results of the present study agreed with that obtained by Willcox et al. (2010) who found that silver nanoparticles containing lenses reduced the bacterial viability and adhesion for the tested strains, 20ppm nano silver showing $>5 \log$ reduction in solution or on the lens surface.

In addition, the $(\mathrm{CSH})$ of the tested strain cells in the presence of different concentrations of $\mathrm{ZnO}$ nanoparticles has been measured because hydrophobicity plays a positive role in biofilm formation. In the current study, the results in Table 2 demonstrated that ZnONPs treatment dose- dependently reduced the $\mathrm{CSH}$. Where the reduction ranged from (92.9 to $18.5 \%$ ), from (93.0 to $32.8 \%$ ) with $P$. aeruginosa 10 and Ent. Cloacae 13, respectively. The tested strains displayed a highly significant decrease in $\mathrm{CSH}$ $(\mathrm{P}<0.05)$ by the treatment using $0.05,0.25,0.5$, 1.25 and $2.5 \mathrm{mM}$ of $\mathrm{ZnONPs}$ in comparison with the control.

Lee et al. (2014) reported that cell surface hydrophobicity plays a critical role in the attachment to the surfaces. The influence of $\mathrm{CSH}$ on adhesion of microorganisms to biotic and abiotic surfaces in medicine has both negative and positive aspects. Hydrophobic microorganisms cause the damage of surfaces by biofilm formation; one of the solutions of this problem is using implants from anti-biofilm materials that can delay or completely avoid the adhesion of microorganisms. Menno et al. (2011) suggested another approach of preventing surfaces from bacterial colonization which was a modification of surfaces by coating them with noble metals, i.e., silver nanoparticles. The silver nanoparticles can be either deposited directly on the surface of medical devices, or applied in a polymeric surface coating.

\section{Field emission electron microscopy}

To study the colonization of the tested organisms on the surface of CCLs as a result of lysozyme deposition as well as the action mechanism of $\mathrm{ZnO}$ nanoparticles' ability to colonize and their morphology should be identified. SEM micrograph showed a colonization of rod cells of $P$. aeruginosa 10 covering contact lenses surface (Fig. 6A), while Fig. 6B demonstrated that lysozyme deposition caused heavy clumps of the tested cells compared to uncoated lens, which are embedded in crystalline patches. Treatment using ZnONP $(2.5 \mathrm{mM})$ as shown in Fig. $6 \mathrm{C}$ demostrated few numbers of scattered deformed cells. Similarly, SEM showed the effect of lysozyme \&ZnONPs on the number of adherent cells of Ent. cloacae 13 covering CCLs. Figure 7B elucidated the ability of lysozyme to increase the number of adherent cells. Meanwhile ZnONPs dramatically restricted the bacterial colonization as can be obviously discriminated in Fig. 7C comparing uncoated lense (Fig. 7A).

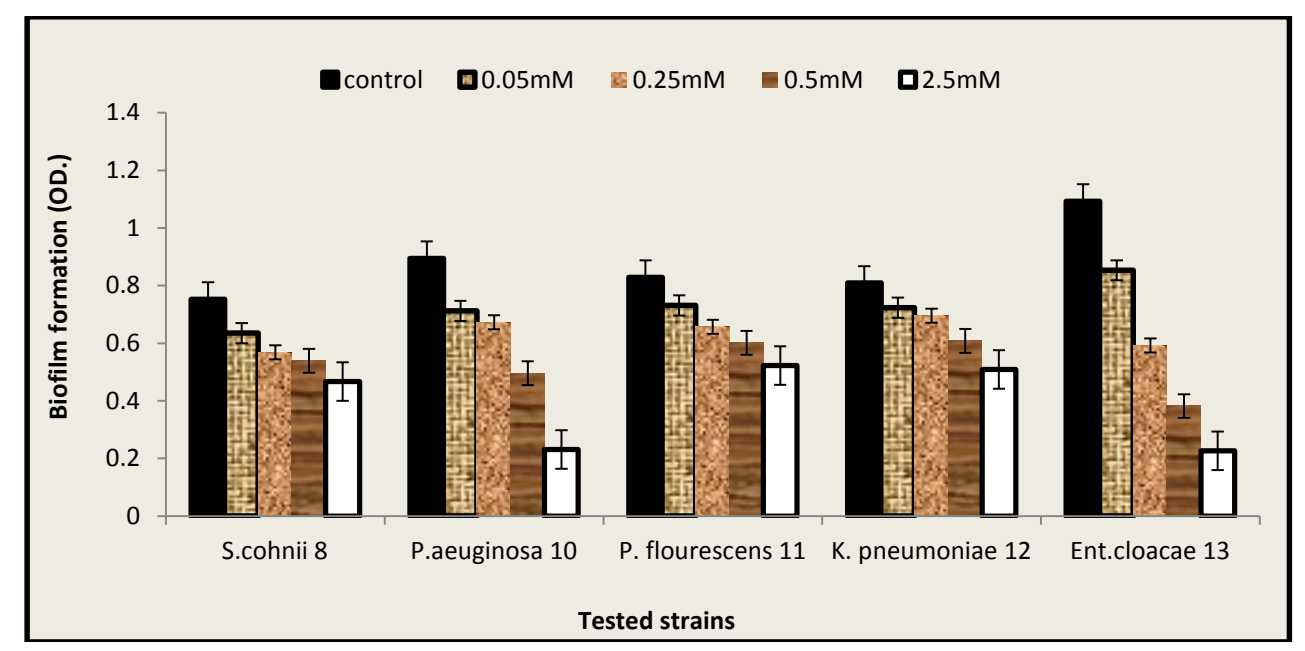

Fig. 4. Anti-biofilm effect of different concentrations of ZnONPs on the tested strains. 


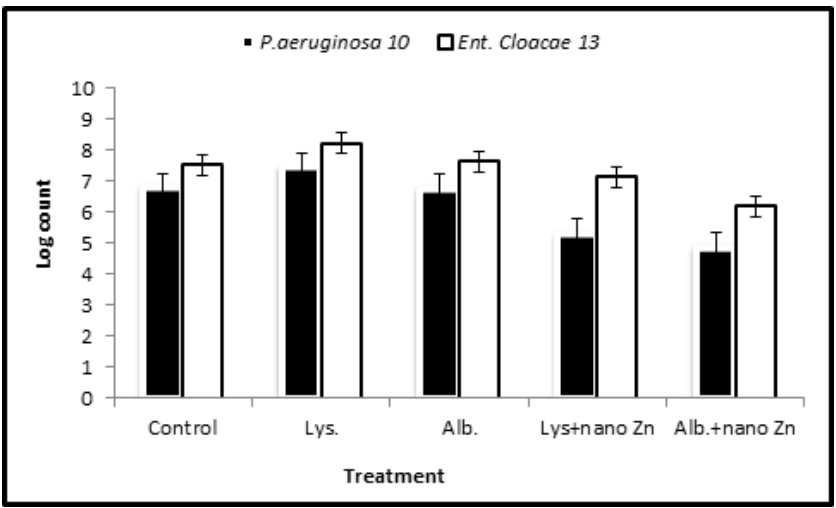

Fig. 5. Effect of ZnONPs on microbial count of the selected strains after deposition of (lysozyme and bovine serum albumin).

TABLE 2. Surface hydrophobicity of the selected strains after treatment with different concentrations of ZnONPs.

\begin{tabular}{lcc}
\hline Treatment & P. aeruginosa $\mathbf{1 0}$ & Ent. cloacae 13 \\
\hline Control & $100^{\mathrm{a}^{*}}$ & $100^{\mathrm{a}}$ \\
$0.05 \mathrm{mM}$ & $92.9^{\mathrm{a}} \pm 0.48$ & $93.0^{\mathrm{a}} \pm 0.93$ \\
$0.25 \mathrm{mM}$ & $79.1^{\mathrm{b}} \pm 0.14$ & $81.3^{\mathrm{b}} \pm 0.90$ \\
$0.5 \mathrm{mM}$ & $62.4^{\mathrm{c}} \pm 0.20$ & $68.8^{\mathrm{c}} \pm 2.90$ \\
$1.25 \mathrm{mM}$ & $37.1^{\mathrm{d}} \pm 0.18$ & $45.1^{\mathrm{d}} \pm 3.60$ \\
$2.5 \mathrm{mM}$ & $18.5^{\mathrm{e}} \pm 0.26$ & $32.8^{\mathrm{e}} \pm 6.44$ \\
\hline
\end{tabular}

*Percentage \pm the standard error; Mean values followed by different superscript (within the same column) is significantly different at the $5 \%$ level.

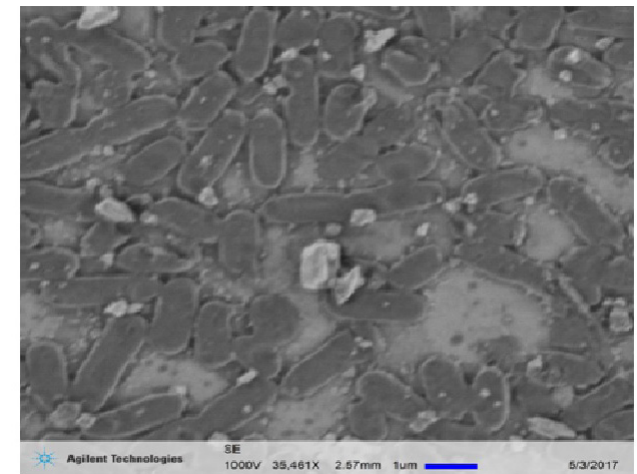

A
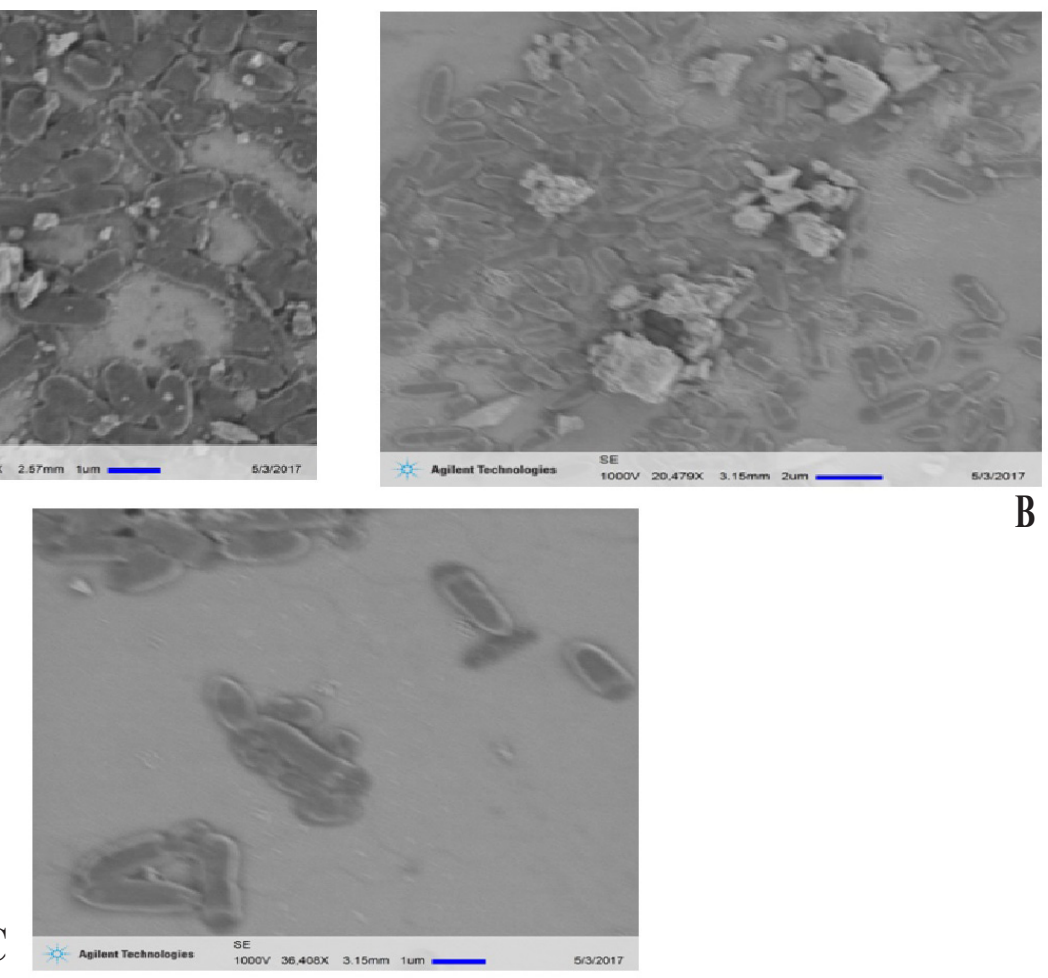

B

Fig. 6. Scanning electron micrographs: (A) Artificially contaminated CCL with $P$. aeruginosa strain, (B) Artificially contaminated CCL with $P$.aeruginosa and coated with lysozyme and (C) Artificially contaminated CCL with $P$.aeruginosa, coated with lysozyme and treated with $\mathrm{ZnONPs.}$ 

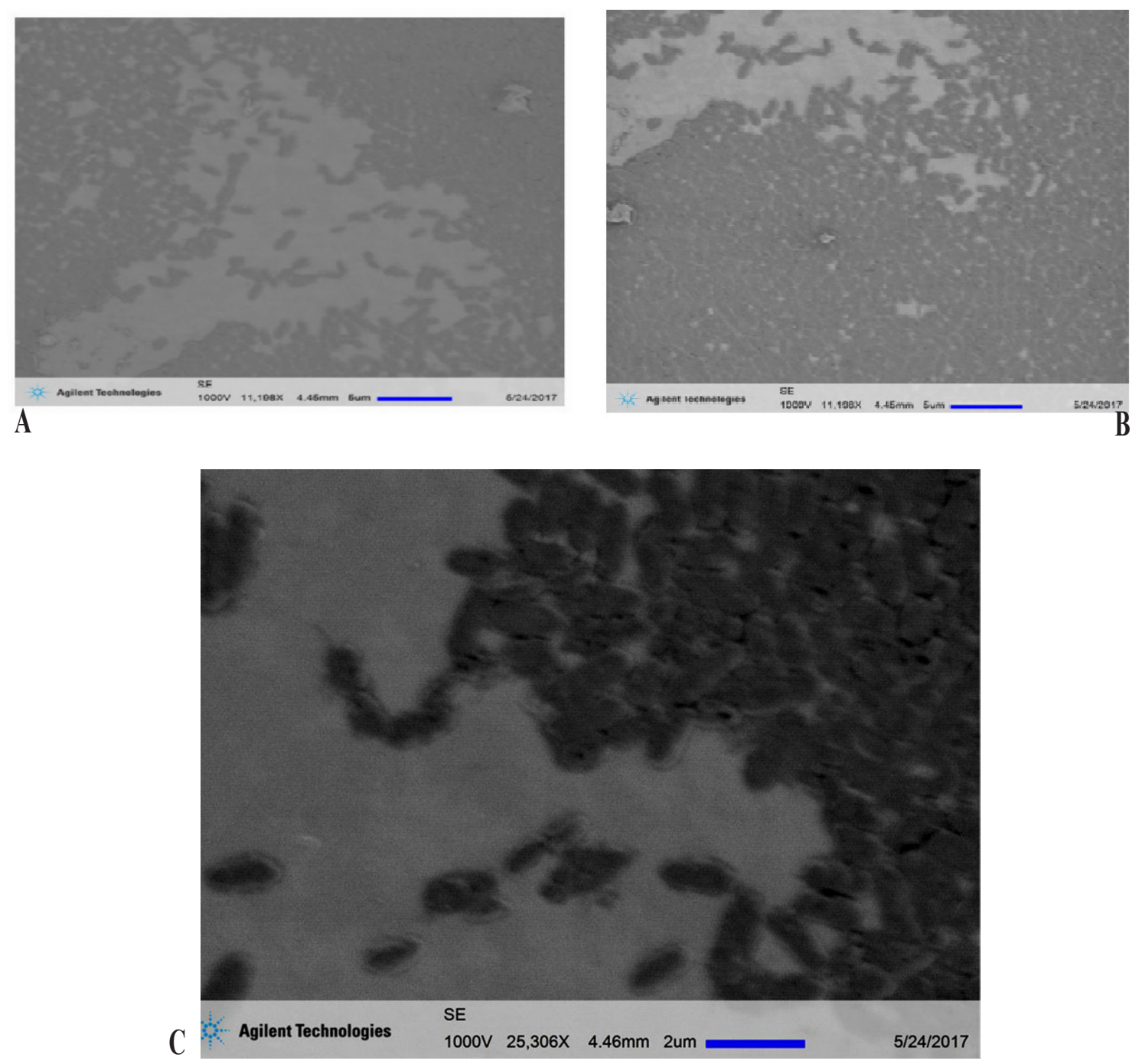

Fig. 7. Scanning electron micrographs: (A) Artificially contaminated CCL with Ent. cloacae strain, (B) Artificially contaminated CCL with Ent. cloacae and coated with lysozyme and (C) Artificially contaminated CCL with Ent. cloacae coated with lysozyme and treated with ZnONPs.

Pati et al. (2014) showed that ZnO NPs can reduce cell surface hydrophobicity and down regulate the transcription of oxidative stressresistance genes in bacteria. Also, Elavarasan et al. (2016) reported that the reasons for bioactivity of ZnONPs against bacteria are due to their binding to the bacterial membrane through electrostatic forces. ZnONPs are directly involved in killing bacteria, or destruction of cell membrane which caused by penetration of the $\mathrm{ZnONPs}$ or the generation of highly reactive species. It is clear that the nanoparticles anchor the cell at several sites and cause damage at various locations in the membrane, which could result in cell lysing. If the mechanism of $\mathrm{ZnONPs}$ disrupts the outer membrane components such as poirn and lipopolysaccharide and considering that Gram-positive bacteria do not have an outer layer, thus, it could be concluded that the rate of cell destruction should be less severe compared to that of gram-negative bacteria (El-Batal et al., 2018).

\section{The Microbial load of the packaging solution}

FDA (2001) stated that for eye area and baby products; microbial counts should not be more than $500 \mathrm{CFU} / \mathrm{g}$ or $\mathrm{ml}$. In this investigation out of 20CCL solutions, fifteen samples (75\%) were contaminated with bacterial growth in the range from $5.0 \times 10^{1}$ to $2.0 \times 10^{8} \mathrm{CFU} / \mathrm{ml}$ and no fungal growth was detected after incubation 
period (3-5 days). Data presented in Table 3 exhibit that most of the tested solutions were highly contaminated with bacteria exceeding the permissible limits. Therefore, these samples were exposed to increasing doses of gamma radiation. According to the results recorded in Table 3 , the decontamination dose was determined to be 6.0kGy. Abo-State et al. (2012) reported that out of ten samples from solution lenses, eight were bacterial contaminated in the range from $2 \mathrm{CFU} /$ $\mathrm{ml}$ to $1.5 \times 10^{2} \mathrm{CFU} / \mathrm{ml}$.

Ionizing radiation such as gamma rays has long been recognized as a method for destroying spoilage and pathogenic microorganisms. It is well known that exposure of bacterial cells to ionizing radiation presents an additional stress to the cells which tends to disturb their organization, nucleic acids, especially DNA which is the primary target for cell damage from ionizing radiation. Gamma radiation induced three types of damage in DNA, single strand breaks, double strand breaks; nucleotide damage and disrupters of protein-DNA complex (Eon et al., 2001 and McLean et al., 2004).

\section{Conclusions and Recommendation}

The present results indicated that nano-sized $\mathrm{ZnO}$ particles have an important inhibiting capacity of bacterial adhesion. Coating CCLs with applied proteins increased adhesion of the tested strains when compared to un-coated lenses. Also, it was found that $\mathrm{ZnONPs}$ reduced bacterial viability of the tested strains on protein coated CCLs. In addition, this study stated that $\mathrm{CSH}$ was positively correlated to biofilm formation. Finally; ionizing radiation effectively eliminated the populations of the highly contaminated samples of packaging solutions.

Due to the high emerged multidrug resistant microorganisms, appropriate concentration of ZnONPs was recommended to be added to the packaging solutions of CCLs which are presterilized by gamma- radiation.

TABLE 3. Bacterial counts of CCLs packaging solutions as affected by different doses of gamma-radiation.

\begin{tabular}{|c|c|c|c|c|c|c|c|}
\hline \multirow{2}{*}{ Sample no. } & \multicolumn{7}{|c|}{ Dose (kGy) } \\
\hline & 0.0 & 1.0 & 2.0 & 3.0 & 4.0 & 5.0 & 6.0 \\
\hline 1 & $5 \times 10^{6}$ & $22 \times 10^{4}$ & $8 \times 10^{3}$ & $15 \times 10^{2}$ & $29 \times 10^{1}$ & $3 \times 10^{1}$ & ---- \\
\hline 2 & $7.8 \times 10^{1}$ & ----- & ----- & ----- & ----- & ----- & ----- \\
\hline 3 & ND & ----- & ----- & ----- & ----- & ----- & ----- \\
\hline 4 & $2 \times 10^{8}$ & $3 \times 10^{6}$ & $8 \times 10^{5}$ & $12 \times 10^{3}$ & $6 \times 10^{2}$ & $12 \times 10^{1}$ & ----- \\
\hline 5 & ND & ------ & ----- & ----- & ----- & ----- & ----- \\
\hline 6 & $3 \times 10^{5}$ & $6 \times 10^{4}$ & $3 \times 10^{3}$ & $2 \times 10^{2}$ & $7 \times 10^{1}$ & ----- & ----- \\
\hline 7 & $5 \times 10^{4}$ & $18 \times 10^{3}$ & $8 \times 10^{2}$ & $6 \times 10^{1}$ & ----- & ----- & ----- \\
\hline 8 & $5.0 \times 10^{1}$ & ---- & ----- & ----- & ----- & ----- & ----- \\
\hline 9 & $6 \times 10^{3}$ & $13 \times 10^{2}$ & $5 \times 10^{2}$ & $15 \times 10^{1}$ & ----- & ----- & ----- \\
\hline 10 & $8 \times 10^{4}$ & $2 \times 10^{3}$ & $6 \times 10^{2}$ & $8 \times 10^{1}$ & ----- & ------ & ----- \\
\hline 11 & $2 \times 10^{2}$ & $6 \times 10^{1}$ & ND & ----- & ----- & ----- & ----- \\
\hline 12 & ND & ----- & ----- & ------ & ------ & ----- & ----- \\
\hline 13 & $5 \times 10^{2}$ & $3 \times 10^{2}$ & $8 \times 10^{1}$ & ----- & ----- & ----- & ----- \\
\hline 14 & $4 \times 10^{5}$ & $8 \times 10^{3}$ & $4 \times 10^{3}$ & $2 \times 10^{2}$ & $7 \times 10^{1}$ & ----- & ----- \\
\hline 15 & ND & ------ & ----- & ------ & ------ & ----- & ----- \\
\hline 16 & $3 \times 10^{5}$ & $6 \times 10^{3}$ & $8 \times 10^{2}$ & $13 \times 10^{1}$ & ----- & ------- & ----- \\
\hline 17 & $2 \times 10^{7}$ & $4 \times 10^{6}$ & $7 \times 10^{5}$ & $8 \times 10^{3}$ & $2 \times 10^{2}$ & $25 \times 10^{1}$ & ----- \\
\hline 18 & $1 \times 10^{8}$ & $7 \times 10^{6}$ & $3 \times 10^{6}$ & $5 \times 10^{5}$ & $3 \times 10^{3}$ & $6 \times 10^{1}$ & ----- \\
\hline 19 & ND & ---- & ----- & ------ & ----- & ----- & ----- \\
\hline 20 & $7 \times 10^{5}$ & $2 \times 10^{3}$ & $5 \times 10^{2}$ & $32 \times 10^{1}$ & ----- & ----- & ----- \\
\hline
\end{tabular}




\section{Declaration of Conflicting Interests}

The author(s) declared no potential conflicts of interest with respect to the research, authorship, and/or publication of this article.

\section{References}

Abidi, S.H., Sherwani, S.K., Siddiqui, T.R., Bashir, A. and Kazmi, S.U. (2013) Drug resistance profile and biofilm forming potential of Pseudomonas aeruginosa isolated from contact lenses in KarachiPakistan. BMC Ophthalmology, 13, 57.

Abo-State, M.A.M., Helimish, F.A., Husseiny, Sh.M. and Zickry, A.R.A. (2012) Reduction of health hazard of Bacillus species contaminating solution lenses and baby powder by Imipenem and Gamma radiation. World Applied Sciences Journal, 19(6), 856-866. Doi: 10.5829/idosi.wasj. 19.06.2777

Al- Mujaini, A., Al- Karusi, N., Thakral, A. and Wali, U.K. (2009) Bacterial keratitis: Perspective on epidemiology, clinico- pathogenesis, diagnosis and treatment. SQU MED, 9(2), 148-195.

Ansari, M. A., Khan, H.M., Khan, A.A., Cameotra, S.S. and Pal, R. (2014) Antibiofilm efficacy of silver nanoparticles against biofilm of extended spectrum b-lactamase isolates of Escherichia coli and Klebsiella pneumoniae. Appl. Nanosci. 4, 859868. DOI: $10.1007 / \mathrm{s} 13204-013-0266-1$

Bauer, A.W., Kirby, W.M., Sherris, J.C. and Turck, M. (1966) Antibiotic susceptibility testing by a standardized single disk method. Am. J. Clin. Pathol. 45(4), 493-496.

Benhmidoune, L., Bensemlali, A., Bouazza, M., Karami, R., El Mansouri, H. and El Belhadji, M. et al. (2013) Contact lens related corneal ulcers: Clinical, microbiological and therapeutic features. J. Fr. Ophtalmol. 36(7), 594-9.

Chan, K.Y., Choa, P. and Boost, M. (2014) Microbial adherence to cosmetic contact lenses. Contact Lens \& Anterior Eye; 37, 267-272.

Christensen, G.D., Simpson, W.A., Younger, J.A., Baddour, L.M., Barrett, F.F. and Melton, D.M. et al. (1985) Adherence of coagulase negative Staphylococci to plastic tissue cultures: Aquantitative model for the adherence of Staphylococci to medical devices. J. Clin. Microbiol. 22, 996-1006.
Clinical and Laboratory Standard Institute recommendations (CLSI) (2007) Performance Standards for Antimicrobial Susceptibility Testing, $17^{\text {th }}$ Informational Supplement, Clinical and Laboratory Standards, Wayne, PA.

Dhillon, G.S., Kaur, S. and Brar, S.K. (2014) Facile fabrication and characterization of chitosan-based zinc oxide nanoparticles and evaluation of their antimicrobial and antibiofilm activity. Int Nano Lett. 4, 107. DOI 10.1007/s40089-014-0107-6.

Dyavaiah, M., Phaniendra, A. and Sudharshan, S.J. (2015) Microbial keratitis in contact lens wearers. JSM Ophtalmol. 3(3), 1036.

Elavarasan, N., Kokila, K. Inbasekar, G. and Sujatha, V. (2016) Evaluation of photocatalytic activity, antibacterial and cytotoxic effects of green synthesized $\mathrm{ZnO}$ nanoparticles by Sechium edule leaf extract. Res Chem Intermed. DOI 10.1007/ s11164-016-2830-2

El-Batal, A.I., Farag, M., Mosalam, M.M., Ghorab, A.H. and Elbarbary, A.M. (2018) Antimicrobial, antioxidant and anticancer activities of zinc nanoparticles prepared by natural polysaccharides and gamma radiation. International Journal of Biological Macromolecules, 107, 2298-2311.

Eon, S., Culard, F., Sy, D., Charlier, M. and SpotheimMaurizott, M. (2001) Radiation disrupts proteinDNA complexes through damage to the protein. The lac repressor- operator system. Rad. Res. 156, 110-117.

FDA (U.S FOOD and Drug Adminstration) (2001) "Bacteriological Analytical Manual", $8^{\text {th }}$ ed, Chapter 23, AOAC International, Arlimgton, VA.

Iannitelli, A., Grande, R., Stefano, A., Giulio, M., Sozio, P., Bessa, L.J., Laserra, S., Paolini, C., Protasi, F. and Cellini, L. (2011) Potential antibacterial activity of Carvacrol-Loaded Poly (DL-lactide-co-glycolide) (PLGA) Nanoparticles against Microbial Biofilm. Int. J. Mol. Sci. 12(8), 5039-5051.

Jhanji,V., Sharma,N., Satpthi, G. and Titiyal, J. (2007) Fourth- generation fluroquinolone- resistant bacterial keratitis. Clin. Refract. Surg. 33, 1488-9.

Kackar, S., Suman, E. and Kotian, M.S. (2017) Bacterial and fungal biofilm formation on contact lenses and 
their susceptibility to lens care solutions. Indian J. Med. Microbiol. 35, 80-4.

Lee, J.H., Kim, Y.G., Cho, M.H. and Lee, J. (2014) ZnO nanoparticles inhibit Pseudomonas aeruginosa biofilm formation and virulence factor production. Microbiol Res. 169, 888-896.

Liu, C., Guo, J., Yan, X., Tang, Y., Mazumder, A., $\mathrm{Wu}$, S. and Liang, Y. (2017) Antimicrobial nanomaterials against biofilms: An alternative strategy. Environmental Reviews. 25(2), 225-244.

Luensmann, D. and Jones, L. (2008) Albumin adsorption to contact lens materials. Contact Lens and Anterior Eye, 31(4), 179-187.

Mah, T.F. and O'Toole, GA. (2001) Mechanisms of biofilm resistance to antimicrobial agents. Trends Microbiol. 9, 34-9.

Mathews, S.M., Spallholz, J.E., Grimson, M.J., Dubielizing, R.R., Gray, T. and Reid, T.W. (2006) Prevention of bacterial colonisation of contact lenses with covalently attached selenium and effects on the rabbit cornea. Cornea, 25, 806-814.

Mathur, T., Singhal, S., Khan, S., Upadhyay, D.J., Fatma, T. and Rattan, A. (2006) Detection of biofilm formation among the clinical isolates of staphylococci: An evaluation of three different screening methods. Indian J. Med. Microbiol. 24(1), 25-9.

McLean, R.J.C., Bates, C.L., Barnes, M.B., McGowin, C.L. and Aron, G.M. (2004) Methods of studying biofilms. In: "Microbial Biofilms", M. Ghannoum and G.A.O'Toole (Ed.), pp. 379-413. ASM Press, Washington, D.C.

Menno,L., Knetsch,W. and Koole, L. (2011) New strategies in the development of antimicrobial coatings: The example of increasing usage of silver and silver nanoparticles. Polymers, 3, 340-366. DOI: $10.3390 /$ polym 3010340

Ohashi, Y., Dogru, M. and Tsubota, K. (2006) Laboratory findings in tear fluid analysis. Clin Chim Acta. 369, 17-28.

Omali, N.B., Zhu, H., Zhao, Z. and Willcox, M.P.D. (2013) Protein deposition and its effect on bacterial adhesion to contact lenses. Optometry and Vision Science, 90(6), 557-564.
Pati, R., Mehta, RK., Mohanty, S., Padhi, A., Sengupta, M. and Vaseeharan, B., et al. (2014) Topical application of zinc oxide nanoparticles reduces bacterial skin infection in mice and exhibits antibacterial activity by inducing oxidative stress response and cell membrane disintegration in macrophages. Nanomedicine, 10(6), 1195-208.

Perez, P.F., Minnaard, Y., Disalvo, E.A. and De Antoni, G.L. (1998) Surface properties of bifidobacterial strains of human origin, Appl. Environ. Microbiol. 64, 21-26.

Prasannakumary, C. and Jyothy, PT. (2017) Complications of contact lens. Kerala $J$. Ophthalmol. 29, 68-71.

Pucker, D.A., Thangavelu, M. and Nichols, J.J. (2010) In vitro lipid deposition on hydrogel and silicone hydrogel contact lenses. Investigative Ophthalmology \& Visual Science, 51, 6334-6340.

Ražem, D. (2008) Radiation sterilization of pharmaceuticals. In: "Trends in Radiation Sterilization of Health Care Products", p. 175182. International Atomic Energy Agency. Vienna, Printed by the IAEA in Austria. July 2008.

Sangani, M.H., Moghaddam, M.N. and Forghanifard, M.M. (2015) Inhibitory effect of zinc oxide nanoparticles on Pseudomonas aeruginosa biofilm formation. Nanomedicine Journal, 2(2), 121-128. Online ISSN 2322-5904 http://nmj.mums.ac.ir

Shah, B. and Pokhrel, N. (2012) Microbial quality and antibacterial activity of herbal medicines. Nepal Journal of Science and Technology, 13(2), 191-196.

Shimizu, K., Kobayakawa, S., Tsuji, A. and Tochikubo, T. (2006) Biofilm formation on hydrophilic intraoccular lens material. Cur. Eye. Res. 31, 989997.

Sewell, A., Dunmrie, J., Wehann, M., Rowe, T. and Bouhenni, R. (2014) Proteomic analysis of keratitis associated Pseudomonas aeruginosa. Molecular Vision, 20, 1182-1191.

Steel, R.G.D. and Torrie, J.H. (1980) "Principles and Procedures of Statistics", McGraw Hill Book Co. Inc. New York.

Subbaraman, L.N.' Borazjani, R., Zhu, H., Zhao, Z., Jones, L. and Willcox, M.D. (2011) Influence of 
protein deposition on bacterial adhesion to contact lenses. Optometry \& Vision Science, 88(8), 959-966.

Sueke, H., Kaye, S. and Neal, T. et al. (2010) Minimum inhibitory concentrations of standard and novel antimicrobials for isolates from bacterial keratitis. Invest. Ophthalmol.Vis. Sci. 51, 2519-2524.

Taylor, R.L., Willcox, M.D., Williams, T.J. and Verran, J. (1989) Modulation of bacterial adhesion to hydrogel contact lenses by albumin. Optom. Vis. Sci. 75, 23-29.

Thakur, A., Chauhan, A. and Willcox, M.D. (1999) Effect of lysozyme on adhesion and toxin release by Staphylococcus aureus. Aust. N Z J Ophthalmol. 27, 224-227.
Willcox, M.D. (2012) Management and treatment of contact lens - related Pseudomonas keratitis. Clin. Ophthalmol. 6, 919-924.

Willcox, M.D., Harmis, N.C. and Williams, T.H. (2001) Bacterial interactions with contact lenses; effects of lens material, lens wear and microbial physiology. Biomaterials, 22, 3235-3247.

Willcox, M.D., Hume, E.B., Vijay, A.K. and Petcavich, R. (2010) Ability of silver impregnated contact lenses to control microbial growth colonisation. $J$. Optom. 3, 143-148.

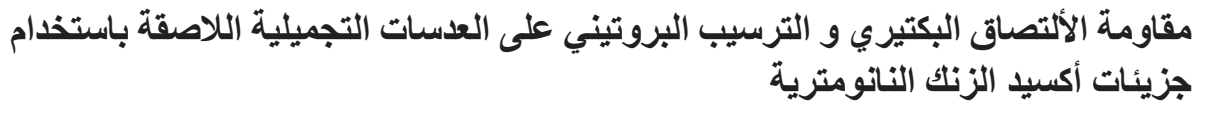

إيمان عربى(1)، حنان سبد البسطويسى(2) و سهام يوسف الطبلاوى (2)

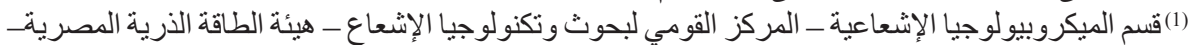

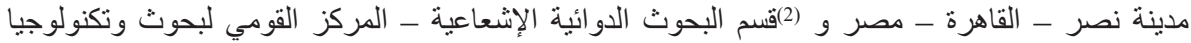

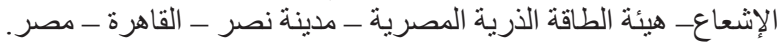

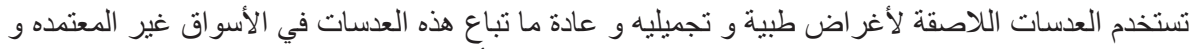

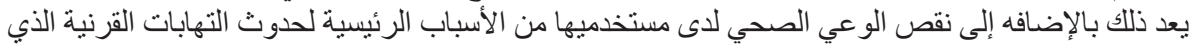

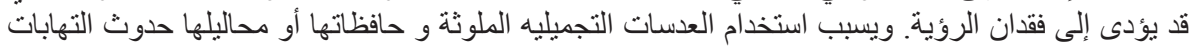
القرنية مما يساعد على إلتصاق الميكروبات الممرضة و تكوين الفيلم الحيوي على سطح العدسة.

وتهدف هذه الدر اسة إلى تقييم حساسية بعض السلالات البكتيرية المعزولة من عدسات تجميلية مستعملة

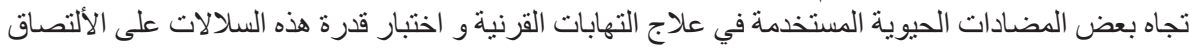

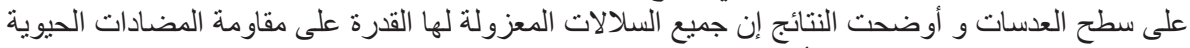

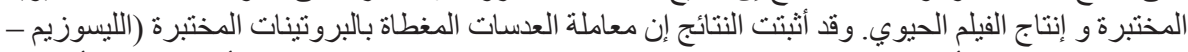

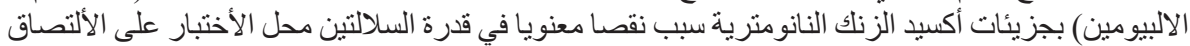

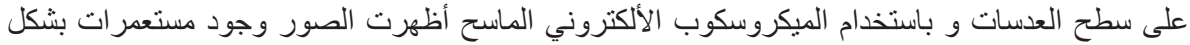

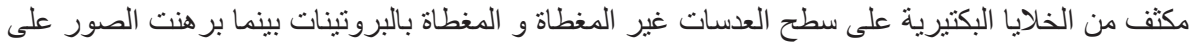

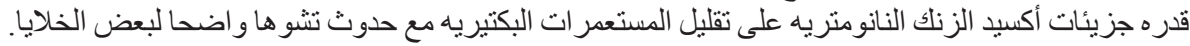

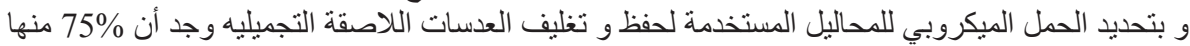

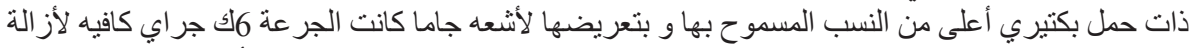

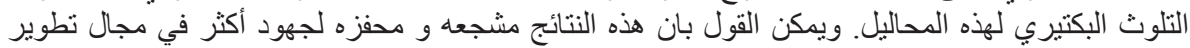
مضادات جديدة ضد العدوى الميكروبية على العدسات اللاصقة التجميليه. 